\title{
Excessive Heating Identified
}

National Cancer Institute

\section{Source}

National Cancer Institute. Excessive Heating Identified. NCI Thesaurus. Code C139518.

The device delivered more heat than intended or expected during operation. This applies to devices which are intended to deliver heat. 